\title{
Introducing exergy analysis in life cycle assessment: A case study
}

\author{
Teresa M. Gulotta $^{1 *}$, Francesco Guarino ${ }^{1}$, Marina Mistretta ${ }^{2}$, Maurizio Cellura $^{1}$, Giulio Lorenzini ${ }^{3}$ \\ ${ }^{1}$ University of Palermo, DEIM Department Viale delle Scienze, Building 9., Palermo 90128, Italy \\ ${ }^{2}$ University of Reggio Calabria, PAU Department, Salita Melissari, Reggio Calabria 89124, Italy \\ ${ }^{3}$ University of Parma, Department of Engineering and Architecture, Parco Area delle Scienze no. 181/A, Parma 43124, Italy
}

Corresponding Author Email: teresamaria.gulotta@unipa.it

https://doi.org/10.18280/mmep.050302

Received: 18 February 2018

Accepted: 22 April 2018

\section{Keywords:}

exergy analysis, Life Cycle Assessment ( $L C A)$, Cumulative exergy demand (CExD), technology obsolescence, biomass boiler

\begin{abstract}
Life Cycle Assessment (LCA) is a methodology for assessing the potential environmental aspects associated with a product or service along its life cycle. However, in the case of energy technologies, it is suggested that the LCA of a product encompasses also further aspects other than environmental aspects and primary energy calculations. In particular, to optimize the reduction of raw materials during the whole life cycle, it is important to introduce the assessment of the irreversibility, applying the exergy analysis.

In this paper, an integrated approach of exergy analysis and LCA is proposed, developing the Life-cycle quality index able to suggest potential exergy inefficiencies and the Life Cycle irreversibility index that helps the comparison of processes and products having the same functional unit. In addition, the paper introduces a new dimensionless index, the Technology Obsolescence index, to quantify the technological obsolescence of the energy system examined, merging the energy performance and the material, used both with the same units to achieve a design optimization. The indices proposed are applied to the whole life cycle of a biomass boiler. The results identify that hotspots can be traced in the use stage of the real biomass boiler, where the potential recoverable exergy has an incidence of $17.4 \%$ on the total exergy destroyed. Also, in the manufacturing stage, the cooking process produces the highest irreversibilities of the production stage.
\end{abstract}

\section{INTRODUCTION}

Life Cycle Assessment (LCA) [1] is a methodology for assessing the potential environmental aspects associated with a product or service. The application of such a methodology is wide and much diversified between energy-related products, standard and renewable energy-based technologies, energy services, and companies.

The methodology, based on steady-state calculations and regulated on the family of ISO14000 [2], regulations the whole life cycle of products and services encompassing all the life cycle stages, from the extraction of resources, manufacturing and production, installation and use phase, up to the end-oflife.

The results of this kind of analysis are typically energy use and various environmental impacts per life cycle step. Such impacts are usually very diversified and able to target a wide range of issues and impacts: from the ionizing radiation hazards to climate change, from cancer inducing radiations to ozone depletion potential [3].

LCA is regularly used in the field of energy systems sustainability assessment [4-5], in several applications, ranging from heating and cooling technologies analysis, burners, photovoltaic systems etc. Such studies are usually based on an integration between real or simulated analysis of the use stage [6-7] and an in-depth study of the bill of materials and of the construction and end-of-life stages of the system.

The analysis is usually carried out with the support of environmental databases [8-9], which include a large number of energy systems and industrial processes data, characterized by site-specific and environmental impacts, which can be harmonized and connected to each other to attain the final impact assessment.

However, what LCA can do only to a limited extent is to fully characterize and describe in detail the quality of energy interaction among the parts of the system, or in other words, to establish correlations inspired by the second Law of the thermodynamics [10]. As such, LCA is not fully able to grasp the quality of the energy vectors used in the system or rather to determine the technological obsolescence of the systems in play.

While some methodologies currently exist [11-14] to approach the Exergy analysis in the LCA approach, the only available indicator, upon which most of the previous approaches are based, is currently the Cumulative Exergy Demand (CExD) [15], which has been recognized as the distinctive method for life cycle influence assessment and is now part of Ecoinvent database [8] and all major LCA software [16].

The Cumulative Exergy Demand (CExD) is defined as the sum of exergy of all energy and material resources required to provide a process or product. The mathematical notation of CExD was chosen by Bösch in [15] to stress the similarities to Cumulative energy demand (CED). The difference between this two methods is that the CED represents the direct and indirect energy use throughout the life cycle while the CExD calculates the whole exergy input to a system by computing exergy of fuels and chemical potential. 
As such, it uses a sort of black box logic that makes it difficult to determine the irreversibility of a transformation and calculating, therefore, the most exergy-intensive steps of the life cycle of an energy system.

The paper proposes an extension of the concept of CExD to calculate the amount of destroyed exergy for every step of the life cycle of an energy system [17]. The approach has the objective to suggest some indicators to be included in the LCA of energy system by introducing the exergy analysis, in order to help decision-makers in the comparison of similar technologies and have a deeper insight in the life cycle performance of such systems.

\section{METHODOLOGY}

For a given system that does not experience mass flow, exergy can be defined as the maximum amount of work that can be extracted while the system evolves to the equilibrium with the environment. Exergy can be calculated as in [14]:

$$
\begin{aligned}
& E x=U-U_{0}-T_{0}\left(S-S_{0}\right)+P_{0}\left(V-V_{0}\right)+ \\
& +\sum_{i=1}^{n} n_{i}\left(\mu_{i}-\mu_{0 i}\right)
\end{aligned}
$$

Where $\mathrm{U}$ is the internal energy $[\mathrm{MJ}], \mathrm{T}$ is the temperature $[\mathrm{K}], \mathrm{S}$ is the entropy of the system $[\mathrm{MJ} / \mathrm{K}], \mathrm{P}$ is the pressure [atm], $\mathrm{V}$ is the volume of the system $\left[\mathrm{m}^{3}\right], \mathrm{n}_{\mathrm{i}}$ is the mole fraction of the specific element $i[\mathrm{~mol}], \quad i$ is the chemical potential of the $\mathrm{i}$-th element $[\mathrm{MJ} / \mathrm{mol}]$. Suffix 0 denotes that the reference system is assumed to be at standard environmental temperature $\mathrm{T}_{0}$ (usually $298.15 \mathrm{~K}$ ) and pressure (usually 1 atmosphere)[12].

According to Eq. (1), the calculation of exergy takes into account the mass fractions of each compound, including resources, products, and wastes [18].

To calculate the exergy loss during a process, an exergy balance can be used, formulated as in Eq.2.

$$
\Delta E x=E x_{i}-E x_{p}-E x_{w}
$$

where Ex is exergy and the indices i, p and w refer respectively to inputs, useful products, and waste products; $\Delta \mathrm{Ex}$ indicates the destruction of exergy during the process.

The exergy efficiency of a generic process is defined as follows in Eq.3:

$$
\varepsilon=\frac{E x_{p}}{E x_{i}}
$$

This means that the exergy efficiency is calculated as the ratio of the exergy of the useful products to the input exergy.

By following the classical definition of exergy (reported in Eq.1), it is possible to correlate exergy efficiency to the concept of quality of a process or a product. The quality of a product can, therefore, be represented through a dimensionless index and is calculated as the ratio between the useful exergy derived from the process and the whole exergy that is used as input throughout its life cycle. The proposed index can be defined as Life-cycle quality index $(\Psi$ ) and is calculated as in Eq. 4:

$$
\Psi=\frac{\sum_{k=1}^{n} E x_{p, k}}{\sum_{k=1}^{n} E x_{i, k}}
$$

This is the ratio of the exergy of the outputs of a system to the exergy inputs of the same system (Calculated through CExD). If the numerator is defined as Useful Cumulative Exergy (UCEx), equation 4 can be reworked as in Eq.5

$\Psi=\frac{U C E x}{C E x D}$

The UCEx of the products or/and processes reports the useful effects (in terms of exergy) that an energy system or a process can provide, include the potential recycling, the potential exergy that can be recovered from high temperature fluid flows, the exergy of the potential process scraps saved, the exergy linked to heat and electricity produced during the whole life cycle by an energy system. In particular, it can be calculated as the sum of different contributions as shown in Eq.6:

$$
U C E x=\underbrace{\sum Q(t)\left(1-\frac{T_{0}(t)}{T}\right)+\sum_{t} E x_{e l}(t)}_{\text {exergy of flows }}+\underbrace{\sum_{t}\left(E x_{c h}+E x_{e m b}\right)}_{\text {materials exergy }}
$$

where:

- UCEx is the useful cumulative exergy associated with all processes or utilities of the system, [MJ-ex];

- $Q$ is the useful heating flow $[\mathrm{MJ}]$

- $\quad E x$ is exergy [MJ-ex];

- $\quad$ el indicates the exergy related to the generation of electric energy;

- $\quad c h$ indicates the chemical potential of the materials or components that are produced or recycled during a process;

- $\quad e m b$ indicates the embodied exergy of the materials or components that are produced or recycled during a process;

- $\quad T_{0}$ is the temperature of the dead state $[\mathrm{K}]$;

- $T$ is the temperature of the fluid flows that may have useful exergy content;

- $\quad t$ is the useful life of the system.

Materials are considered by looking at their potential recycling (e.g. the aluminum used for the tubes of the boiler), the chemical potential of the products and the embodied exergy linked to the extraction or/and to transport of the raw materials, considered as the useful material effects of the process.

All the aforementioned indexes can be calculated for two different systems:

- the existing "real" system,

- a "highest theoretical efficient (HTE)" system, having a theoretical perfect potential exergy recovery both from materials recycling and heat re-use.

Another relevant important aspect of the exergetic analysis is the possibility to calculate the irreversibility related to the product or to the process. To this aim, a complementary index called the Life Cycle irreversibility index ( $\mathrm{X}$ ) is introduced, defined as in Eq.7

$\mathrm{X}=1-\Psi=1-\frac{U C E x}{C E x D}=\frac{C E x D-U C E x}{C E x D}$ 
Here, considering the assumptions made above and the exergy balance, the difference between the CExD and the UCEx is the sum of the whole exergy lost and destroyed through the life cycle of the product.

The Life Cycle irreversibility index considers, in relative terms, the exergy inefficiency of a process or a system, but if a real system is compared to the best available technology, it is possible to introduce an index that quantifies the technology obsolescence.

In an energy and environmental point of view, technological obsolescence can be associated to the irreversibility connected to the life cycle of the technology: from manufacturing to endof-life. Based on the assumptions made above, technology obsolescence can be represented by the following index, named Technology Obsolescence index $\left(X_{i, j}\right)$, calculated as the ratio between the index $X$ calculated for two different products having the same functional unit: one that performs real processes and the other that carries out HTE processes. Eq. 8 shows the mathematical formulation of $X_{i, j}$.

$\chi_{i, j}=\frac{\mathrm{X}_{i}}{\mathrm{X}_{j}}=\frac{1-\Psi_{i}}{1-\Psi_{j}}=\frac{\left[\left(\sum_{k=1}^{n} C E x D_{k}-\sum_{k=1}^{n} U C E x_{k}\right) / \sum_{k=1}^{n} C E x D_{k}\right]_{i}}{\left[\left(\sum_{k=1}^{n} C E x D_{k}-\sum_{k=1}^{n} U C E x_{k}\right) / \sum_{k=1}^{n} C E x D_{k}\right]_{j}}$

where $\mathrm{n}$ is the number of the $\mathrm{k}_{\mathrm{th}}$ stages considered in a LCA study.

According to Eq.8, $X_{i, j}$ indicates the difference in the energy performance between the real and the theoretical system. It is worth mentioning that all the aforementioned indexes are particularly relevant to the LCA applications either from an aggregated perspective since they allow an analysis of destroyed exergy on a whole system level and also in a disaggregated approach.

\section{THE CASE STUDY}

The case study is a biomass boiler. Its most relevant technical and geometrical data used for the study are reported in Table 1. The boiler is designed to generate a useful nominal power of $46 \mathrm{~kW}$, using pellets as fuel. The thermal efficiency of the boiler is $82.7 \%$. The $2 \%$ of energy is lost in the mantle of the boiler, $13 \%$ in the chimney, and $2.3 \%$ because of the unburned fuel.

Table 1. Technical and geometrical data of the biomass boiler

\begin{tabular}{c|c|c}
\hline Characteristics & Unit & Value \\
\hline Inner diameter of tubes & $\mathrm{mm}$ & 50 \\
Length & $\mathrm{m}$ & 0.6 \\
Width & $\mathrm{m}$ & 0.6 \\
Height & $\mathrm{m}$ & 0.6 \\
Number of tubes & - & 16 \\
Thermal power & $\mathrm{kW}$ & 46 \\
Energy Efficiency & - & $82.70 \%$ \\
K & 343.08 \\
Outlet temperature of exhaust gas $\left(\mathrm{CO}_{2}\right)$ & $\mathrm{K}$ & 390 \\
Outlet temperature of exhaust gas $\left(\mathrm{CO}_{2}\right)$ & $\mathrm{K}$ & 333.15 \\
Outlet temperature of water $\left(\mathrm{H}_{2} \mathrm{O}\right)$ & $\mathrm{K}$ & 288.15 \\
Outlet temperature of water $\left(\mathrm{H}_{2} \mathrm{O}\right)$ & $\mathrm{kg} / \mathrm{s}$ & 0.245 \\
Mass flow of water $\left(\mathrm{H}_{2} \mathrm{O}\right)$ & $\mathrm{kg} / \mathrm{s}$ & 0.831 \\
Mass flow of exhaust gas $\left(\mathrm{CO}_{2}\right)$ &
\end{tabular}

The high heating value for the pellets was considered equal to $19.84 \mathrm{MJ} \cdot \mathrm{kg}^{-1}$, while a low heating value of $18.54 \mathrm{MJ} \mathrm{kg}^{-1}$ and chemical exergy of $20.80 \mathrm{MJ} \cdot \mathrm{kg}^{-1}$ were assumed, in according to [19].

\subsection{Goal and scope definition}

The main goals of the study are to assess the use of exergy throughout the life cycle of a $46 \mathrm{~kW}$ biomass boiler [20] and to estimate the incidence of each life-cycle step on the total exergy use as qualitative resource, to understand how much this technology can be considered obsolescent compared to a HTE one. The analysis of the manufacturing and transport stages is aggregated in the production stage evaluation.

\subsection{Functional unit and system boundaries}

The functional unit (FU) is the generation of $46 \mathrm{~kW}$ of nominal thermal power. The system boundaries include raw materials extraction, transport, manufacturing, use, and maintenance.

The relevant assumptions made for the real biomass boiler are connected to:

- Manufacturing stage - For the manufacturing stage of the boiler, all inputs and outputs in the processes were considered, including the exergy of the materials used in laser cut, turning, refractory materials filling, painting and cooking process.

- Transport- According to the inventory data, for the transport of raw materials, it is assumed that it takes place by truck (about $8000 \mathrm{~km}$ ) and by ship (about $90 \mathrm{~km}$ ),

- Use stage - The operation of the boiler is analyzed through a dynamic simulation, in which heating required by a residential building is calculated for the city of Agrigento, Sicily, Italy. The exergy associated to heat produced is the useful output, while the total exergy destroyed is considered equal to the quantity of the pellet burned during the useful life.

The relevant assumptions made for the HTE biomass boiler are:

- $\quad$ Manufacturing stage - For the best manufacturing stage, it is assumed that process scraps are recovered (steel, water, cardboard, and plastic film), and that the corresponding exergy content is saved. The potential energy recovery in the upstream and downstream processes is not taken into account.

- Use stage - In the operation of the boiler, the complete recovery of the enthalpy potential of the exhaust gases is possible.

For each of these stages the following indexes were calculated:

- $\quad$ Cumulative Exergy Demand (CExD);

- Useful Cumulative Exergy(UCEx);

- $\quad$ Life Cycle Quality Index ( $\Psi)$;

- $\quad$ Life Cycle Irreversibility Index (X);

- Technology Obsolescence Index $(\chi)$.

\subsubsection{Life cycle inventory}

All LCA modelling assumptions are the same than those discussed in [4]; most data for the main process are primary, while for the upstream and downstream processes secondary data from Ecoinvent [8] were used.

\subsubsection{Results and interpretation}

The application of the CExD on the whole life cycle of the boiler allows assessing the total exergy removed from nature from manufacturing to operation stage. 
These results are shown in Table 2. The categories reported in the table are defined in [15]. It is worth mentioning that these results do not refer to Italian energy generation mixes alone, but account specifically for the geographical origin of all materials and products included in the investigated functional unit.

As described in Eq.6, these values refer to the sum of materials' exergy and the exergy of flows, including energy consumption.

The results show that the use stage is responsible for about $97.58 \%$ of the CExD; followed by the manufacturing stage, which consumes the $2.07 \%$ of the overall exergy consumption. The transport of raw materials and transport and installation of the final product have a share on the total of $0.16 \%$ and $0.18 \%$, respectively.

The stage contribution analysis shows that:

- the percentage incidence of the heat production process is variable from $9.6 \%$ in the category metals to $99.9 \%$ of cumulative biomass exergy demand.
- $\quad$ the major depletion of metals is in the manufacturing stage, with a percentage incidence of $77.4 \%$.

\subsubsection{Production stage}

In the production stage, the cumulative exergy demand for manufacturing and transport is 20.72 GJ. The manufacturing accounts for the $86 \%$ of the total impacts, while transport covers $14 \%$ of the total cumulative exergy demand of all stages, but the boiler use. However the exergy demand for operation is 40 times as high as for production and transport

Because a potential recycling of the materials or a potential energy recovery in secondary processes in the production stage is not taken into account for the real biomass boiler, the cumulative exergy required as input in the manufacturing and transport stage is considered to be completely destroyed.

The exergy of the fuel used for transport is considered negligible, since it does not reach the $0.2 \%$ share on the total exergy of the system. Then, $\mathrm{X}_{\text {real, manufacturing }}$ is equal to 1 .

Table 2. Cumulative exergy demand of the biomass boiler

\begin{tabular}{|c|c|c|c|c|c|}
\hline Category & Unit & Manufacturing & Raw Material Transport & Product Finished Transport & Use stage \\
\hline Non renewable, fossil & MJ & $11,429.03$ & $1,273.49$ & 890.01 & $67,067.61$ \\
\hline Non renewable, nuclear & MJ & $1,522.68$ & 78.96 & 106.58 & $39,282.72$ \\
\hline Renewable, kinetic & MJ & 25.03 & 0.62 & 1.01 & 719.28 \\
\hline Renewable, solar & MJ & 0.30 & 0.01 & 0.02 & 9.63 \\
\hline Renewable, potential & MJ & 627.78 & 14.12 & 45.53 & $4,499.01$ \\
\hline Non renewable, primary & MJ & 0.01 & 0.004 & 0.004 & 0.06 \\
\hline Renewable, biomass & MJ & 967.07 & 2.59 & 50.91 & $713,859.28$ \\
\hline Renewable, water & MJ & 992.60 & 29.02 & 81.93 & $9,741.04$ \\
\hline Non renewable, metals & MJ & $2,174.37$ & 10.52 & 354.84 & 269.16 \\
\hline Non renewable, minerals & MJ & 32.11 & 5.37 & 4.18 & 140.11 \\
\hline Total & GJ & 17.77 & 1.41 & 1.54 & 835.59 \\
\hline
\end{tabular}

On the other hand, in a most efficient manufacturing process, it is supposed that the potential useful effects are connected to the production scraps.

The following production scraps are considered as avoidable:

- $\quad 47 \mathrm{~kg}$ of steel from laser cut process;

- $6 \mathrm{~kg}$ of steel from turning process;

- $\quad 0.4 \mathrm{~kg}$ of cardboard by the refractory materials filling;

- $\quad 0.2 \mathrm{~kg}$ of cardboard from painting process;

- $\quad 54 \mathrm{~kg}$ of water for the industrial process at $317 \mathrm{~K}$ and

1atm;

- $\quad 0.1 \mathrm{~kg}$ of plastic film from the cooking process.

In particular, the useful exergy associated with a unit of the substance of the production scraps is the exergy recovered from the manufacturing process. The eco-profiles of materials and energy sources to model the production process of the scraps are from the Ecoinvent database [8]. The specific useful exergy was calculated by using the characterization factors for CExD, with the exception of water, for which the exergetic contribution related to the enthalpy variations between the output conditions and the dead state has been introduced. The results are shown in Table 3.

A more in-depth analysis of the manufacturing step shows that a relevant share of CExD (approximately $10.47 \mathrm{GJ}$ ) is caused by the cutting and turning steps, that are characterized by higher electricity and raw materials consumption and by higher scraps production that have to be disposed. Table 3 reports only some of the stages of the production process where a potential for exergy recovery occurs.
Table 3. Quality and technology obsolescence of the manufacturing stage for the THE

\begin{tabular}{l|l|l|l|l|l}
\hline & $\mathrm{L}^{1^{*}}$ & $\mathrm{~T}^{2^{*}}$ & $\mathrm{R}^{3^{*}}$ & $\mathrm{P}^{4^{*}}$ & $\mathrm{C}^{5^{*}}$ \\
\hline CExD [GJ] & 9.20 & 1.27 & 0.45 & 0.74 & 0.30 \\
UCEx HTE [GJ] & 0.68 & 0.09 & 0.06 & 0.03 & 0.0008 \\
$\Psi_{\text {HTE }}[-]$ & 0.07 & 0.07 & 0.14 & 0.04 & 0.0028 \\
X $_{\text {HTE }}[-]$ & 0.93 & 0.93 & 0.86 & 0.96 & 0.9972 \\
\hline
\end{tabular}

$\mathrm{L}^{1^{*}}=$ Laser Cut process

$\mathrm{T}^{2 *}=$ Turning process

$\mathrm{R}^{3 *}=$ Refractory Materials Filling process

$\mathrm{P}^{4 *}=$ Painting process

$\mathrm{C}^{5^{*}}=$ Cooking process

Table 3 shows that the highest exergy impact is connected to the laser cut process, where the steel process scraps are responsible for 0.68 GJex. The potential for recycling increases the life cycle quality index of the real process from 0 (no recycling and exergy recovery supposed) to 0.07 in the laser cut stage, but highest effects are generated in the refractory materials filling process where the life cycle irreversibility index can be reduced from 1 to 0.86 .

The results identify a limited impact of exergy destruction on most of the manufacturing stages. For the laser cut, turning and painting, HTE is equal to 0.07 thus indicating a limited potential for exergy recovery in these stages. More attention could be instead paid to the refractory materials filling process, where this value reaches 0.14 , thus indicating higher irreversibilities. 


\subsubsection{Operation stage}

For the operation stage, a simplified boiler model is proposed. The following assumptions are made in this analysis:

- $\quad$ The boiler system operates in a non-steady state;

- $\quad$ The temperatures are reported in Table 1;

- $\quad$ Kinetic and potential energy and exergy are ignored;

- $\quad$ Air and flue gas are treated as ideal gases;

- The chemical exergy of the fuel is considered as the basis to calculate the exergy demand;

- The physical exergy of the flue gas and of the water flows is used to determine the loss of exergy in the components of the boiler;

- In order to determine the exergy losses, mass, energy and exergy balance must be established. The energy and environmental impacts, owing to the operation step of a system, depend on the climatic conditions of the installation site, and the energy performance of the building-plant system. The dead state considered is at standard conditions $\left(\mathrm{T}_{0}=298 \mathrm{~K}\right.$ and $\left.\mathrm{p}_{0}=1 \mathrm{~atm}\right)$.

The operation step is analyzed through a dynamic simulation, in which heating required by a residential building is calculated for the city of Agrigento, Sicily, Italy. The operation step of the biomass boiler includes the quantity of pellet used for 10h/day for 134 days/year (as scheduled by the Italian law n.74/ 2013[21]) for 15 years. The electricity ecoprofile is the generation mix of the Italian electrical grid. TRNSYS is used for the simulation, weather data used is from METEONORM [22].

Assuming that the final use of the boiler is to ensure the heating of buildings, it is necessary to integrate into the evaluation the characteristics of the building itself. The exergy of the heat produced is equal to $1192.41 \mathrm{MJ}_{\mathrm{ex}}$ in a year, this quantity corresponds to the useful effect of the boiler. In 15 years of useful life, to satisfy the cumulative exergy required by the building, the boiler will consume $835,587.90 \mathrm{MJ}_{\mathrm{ex}}$ equal to 40.17 ton of pellets.

Table 4. Results for the operational step

\begin{tabular}{c|c}
\hline & Operation stage \\
\hline CExD [GJ] & 835.59 \\
UCEx HTE [GJ] & 202.21 \\
UCEx real [GJ] & 64.39 \\
$\Psi_{\text {HTE }}[-]$ & 0.08 \\
$\Psi_{\text {real }}[-]$ & 0.24 \\
$\Psi_{\text {HTE }}[-]$ & 0.76 \\
$\Psi_{\text {real }}[-]$ & 0.92 \\
\hline
\end{tabular}

In an HTE biomass boiler, it was assumed that the useful effect account also for the potential exergy of exhaust gas.

The application of the Life Cycle Quality index and Life Cycle irreversibility index on the process mentioned above is shown in Table 4.

Table 4 shows the results of Life Cycle quality and Life Cycle irreversibility indices for real and for best theoretical boiler, based on the assumptions described above. The most relevant contribution is connected to the exergy recoverable from the high temperature fumes, equal to around 140 GJ.

Since in the case of a boiler, the exergy efficiency is commonly low, the results show that if the exhaust gas is used for the generation of work, the Life Cycle quality of the boiler is incremented from 0.08 to 0.24 , reducing its irreversibility by $17.4 \%$. During the operation stage, the $X_{i, j}$ is 1.21 . In addition, Table 5 shows that $X_{i, j}$ for the whole life cycle is close to the technology obsolescence index of the operation stage (1.21) because the operation stage is responsible by the highest cumulative exergy input $(97.6 \%)$.

Table 5. Results for the whole life cycle of the case study

\begin{tabular}{c|c}
\hline & Life Cycle of the biomass boiler \\
\hline CExD [GJ] & 847.55 \\
UCEx HTE [GJ] & 203.15 \\
UCEx real [GJ] & 64.39 \\
$\Psi_{\text {HTE }}[-]$ & 0.24 \\
$\Psi_{\text {real }}[-]$ & 0.08 \\
$X_{\text {HTE }}[-]$ & 0.76 \\
$X_{\text {real }}[-]$ & 0.92 \\
$X_{i, j}[-]$ & 1.22 \\
\hline
\end{tabular}

These indices take into account different aspects respect to the use of the only energy and environmental point of view, irreversibility avoidable permits to identify which are the best solutions to reduce the exergy destroyed or required from nature.

The Life Cycle irreversibility index permits to calculate the absolute irreversibility produced by the real process, then the technology obsolescence index represents the exergetic class of the sub-system or of the whole system.

\section{CONCLUSION}

The paper reports an application to a biomass boiler of a methodology that complements LCA and exergy analysis.

The current application of exergy calculation in LCA is mainly limited to the Cumulative exergy demand index, which basically refers to the chemical potential of inlet materials flows to a process. In other words, through the use of conversion factors, a value of exergy is connected to a material in input to the LCA analysis.

This methodology has the potential to be easy to implement and be integrated into the matrix-based Life Cycle Assessment calculations. It works best in aggregated analyses, thus considering the system or process investigated as a 'black box'. If the aim of the study is, instead, understanding the performance of sub-systems, and to investigate the losses of exergy along a supply chain, the available methodologies cannot take in consideration in-depth aspects of specific energy systems applications.

Authors propose to take into account these aspects in standard LCA analyses. The Life Cycle quality index $(\Psi)$ is able to suggest potential exergy inefficiencies or potential exergy recovery, and the Technology Obsolescence index $\left(X_{i, j}\right)$ helps the comparison of processes and products having the same function.

Their application to LCA would allow an increase in the depth of the LCA analysis that could benefit both application in the LCA field and the exergy analysis field, as the two methodologies cover two aspects that are very closely related.

In order, for the proposed methodology to work best, it would require an adaptation of LCA databases. Currently, information such as exergy efficiencies of the processes are not usually available.

As such, the indicators proposed were applied to the main processes, where the required calculations could be performed directly by the analyst, but not in the background processes (e.g. extraction of iron and manufacturing of steel used for the 
boiler) where the black-box approach of the current LCA databases did not allow it.

Moreover, in the studies available from literature, exergy and LCA have been applied to analyze a single aspect of the optimization of energy processes, neglecting the degradation of technology over time.

Instead, the analysis proposed in this paper marks the concept of the technological obsolescence of the energy system, emphasizing if a more technologically advanced system is available and/or if there is an obsolescent energy component that can no longer be upgraded.

In fact, the use of the Technological Obsolescence index $\left(X_{i, j}\right)$ helps to identify which new technology could reduce the existing irreversibilities from the manufacturing to end-of-life, minimizing the raw materials harnessed from nature.

\section{REFERENCES}

[1] International Organization for Standardization. (2006). UNI EN ISO 14040. Environmental Management. Life Cycle Assessment. Principles and Framework. Environmental Management-Life Cycle Assessment Principles and Framework, 7557-7557.

[2] International Organization for Standardization. (2015). ISO 14000 - Environmental management - ISO.

[3] Editors G, Shiun Lim J, Shin HoW, Klemeš JJ, Mungkung R, Intrachooto S, et al. (2018). Life cycle assessment of hempstone for green buildings. Chemical Engineering Transactions 63.

[4] Longo S, Mistretta M, Guarino F, Cellura M. (2017). Life Cycle Assessment of organic and conventional apple supply chains in the North of Italy. Journal of Cleaner Production 140: 654-63. https://doi.org/10.1016/j.jclepro.2016.02.049

[5] Cellura M, La Rocca V, Longo S, Mistretta M. (2014). Energy and environmental impacts of energy related products (ErP): A case study of biomass-fuelled systems. Journal of Cleaner Production 85: 359-70. https://doi.org/10.1016/j.jclepro.2013.12.059

[6] Guarino F, Cellura M, Longo S, Gulotta T, Mistretta M, Tumminia G, et al. (2016). Integration of building simulation and Life Cycle Assessment: A TRNSYS Application. Energy Procedia 101: 360-7.

[7] Cellura M, Di Gangi A, Longo S, Orioli A. (2013). An Italian input-output model for the assessment of energy and environmental benefits arising from retrofit actions of buildings. Energy and Buildings 62: 97-106. https://doi.org/10.1016/j.enbuild.2013.02.056

[8] Wernet G, Bauer C, Steubing B, Reinhard J, MorenoRuiz E, Weidema B. (2016). The ecoinvent database version 3 (part I): overview and methodology. The International Journal of Life Cycle Assessment 21(9): 1218-30. https://doi.org/10.1007/s11367-016-1087-8

[9] Baitz M, Makishi C, Kupfer T, In JF, Schuller O, Kokborg M, et al. (2014). GaBi Database \& Modelling Principles. PE International.

[10] Hamsani MN, Liew PY, Walmsley TG, Wan Alwi SR. (2018). Compressor shaft work targeting using new numerical exergy problem table algorithm (Ex-PTA) in sub-ambient processes. Chemical Engineering Transactions 63: 283-8. https://doi.org/10.3303/CET1863048

[11] De Meester B, Dewulf J, Verbeke S, Janssens A, Van
Langenhove H. (2009). Exergetic life-cycle assessment (ELCA) for resource consumption evaluation in the built environment. Building and Environment 44(1): 11-7. https://doi.org/10.1016/j.buildenv.2008.01.004

[12] Huysman S, Schaubroeck T, Dewulf J. (2015). Exergy and cumulative exergy use analysis. Sustainability Assessment of Renewables-Based Products: Methods and Case Studies.

[13] Jørgensen SE. (2000). Application of exergy and specific exergy as ecological indicators of coastal areas. Aquatic Ecosystem Health and Management 3(3): 419-30. https://doi.org/10.1080/14634980008657039

[14] Beccali G, Cellura M, Mistretta M. (2003). New exergy criterion in the "multi-criteria" context: A life cycle assessment of two plaster products. Energy Conversion and Management 44(17): 2821-38. https://doi.org/10.1016/S0196-8904(03)00043-8

[15] Bösch ME, Hellweg S, Huijbregts MAJ, Frischknecht R. (2007). Applying cumulative exergy demand (CExD) indicators to the ecoinvent database. The International Journal of Life Cycle Assessment 12(3): 181-90. https://doi.org/10.1065/lca2006.11.282

[16] Milanovic B, Agarski B, Vukelic D, Budak I, Kiss F. (2017). Comparative exergy-based life cycle assessment of conventional and hybrid base transmitter stations. Journal of Cleaner Production 167: 610-8. https://doi.org/10.1016/J.JCLEPRO.2017.08.176

[17] Stougie L, Van Der Kooi HJ. (2016). Possibilities and consequences of the Total Cumulative Exergy Loss method in improving the sustainability of power generation. Energy Conversion and Management 107: 60-6. https://doi.org/10.1016/j.enconman.2015.09.039

[18] Morris DR, Szargut J. (1986). Standard chemical exergy of some elements and compounds on the planet earth. Energy 11(8): 733-55. https://doi.org/10.1016/03605442(86)90013-7

[19] Song G, Shen L, Xiao J. (2011). Estimating specific chemical exergy of biomass from basic analysis data. Industrial \& Engineering Chemistry Research 50(16): 9758-66. https://doi.org/10.1021/ie200534n

[20] Gulotta T, Guarino F, Cellura M, Lorenzini G. (2017). Constructal law optimization of a boiler. International Journal of Heat and Technology 35(2): 297-305. https://doi.org/10.18280/ijht.350210

[21] Italian law n.74/ 2013. Gazz. Uff. 27 Giugno 2013, n. 149.

[22] Meteotest AG. (2017). Handbook part II: Theory, Global Meteorological Database Version 7 Software and Data for Engineers, Planers and Education (March): 79.

\section{NOMENCLATURE}

$\begin{array}{ll}\text { CExD } & \text { Cumulative Exergy Demand, } \mathrm{J}_{\mathrm{ex}} \\ \mathrm{Ex} & {\text { Exergy, } \mathrm{J}_{\mathrm{ex}}}_{\mathrm{g}} \\ \mathrm{g} & \text { Gravity, } \mathrm{m} / \mathrm{s}^{2} \\ \mathrm{LCA} & \text { Life Cycle Assessment } \\ \text { LCIA } & \text { Life Cycle Impact Assessment } \\ \mathrm{n}_{\mathrm{i}} & \text { Mole Fraction of the Specific Element } \mathrm{i}, \text { mol } \\ \mathrm{Q} & \text { Heat Produced, J } \\ \mathrm{S} & \text { Entropy of the System, J/K } \\ \mathrm{T} & \text { Temperature, K } \\ \mathrm{t} & \text { The Useful Life of the System, h } \\ \mathrm{U} & \text { Internal Energy, J }\end{array}$


UCEx Useful Cumulative Exergy, $\mathrm{J}_{\mathrm{ex}}$ $\mathrm{V}$

$\mathrm{z}$

$\Delta \mathrm{Ex}$ Volume, $\mathrm{m}^{3}$

Height, $\mathrm{m}$

Exergy Destroyed, $\mathrm{J}_{\mathrm{ex}}$

\section{Greek symbols}

$\mathrm{X}$

Life Cycle Irreversibility Index

$\chi_{i j}$

$\varepsilon$

$\Psi$
Technology Obsolescence Index

Exergy Efficiency

Life Cycle Quality Index

\section{Subscript}

0

ch

el

i

mat

$\mathrm{p}$

real

w

HTE
Dead State

Chemical

Electricity

Input

Materials

Product

Real System

Waste

Highest theoretical System 